\title{
Risk Defect on Du Base Frame Product
}

\author{
Agyl Adriyadhi $\mathrm{S}^{1}$ and Moses Laksono Singgih ${ }^{1}$
}

\begin{abstract}
During the production process $D U$ base frame product has been found quite a defect occurrence. Defects occurring during the production process of course affect the cost, time and quality of the product production of PT. X, so it is required a handling to overcome the risk of defects that occur so that the product is free from the risk of defects that do not and improve product quality. The method that can overcome the problem above is to predict the risk of product defect by designing a risk management process framework. The risk management planning process is a stage identifying the risk of defects that have occurred or the risk of malformed defects occurred and then conducting a risk-defect analysis, then evaluating the risks of such defects and risk treatment and Monitoring and review. There are also tools and methods used in this risk management study are fishbone and FMEA. Fishbone is used as a tool as a method to cause identification while FMEA is used in risk analysis to determine risk priority number (RPN). From RPN defects that have the highest value will be taken risk evaluation and risk treatment to prevent the same defect. With this research in hopes of the results of quality, cost and production time in DU Base Frame products can remain consistent and give rise to the awareness of the personnel involved in the product manufacturing process. From risk mitigation results found there are 4 out of 56 risk cases that belong to the high-risk category in the process of milling (RPN 288), blasting (RPN $288 \& 224)$ and painting (256). These risks are then conducted advice on the improvements that are discussed with the team and the costumer and the result of defects that occur reduced even eliminated. The importance of the detailed procedures and the awareness of each personnel involved becomes one of the keys to avoid risk in the production process of a product.
\end{abstract}

Keywords-Risk Management, Defect, Product, Fishbone, FMEA.

\section{INTRODUCTION}

Manufacturing is an activity done to process some raw materials or an item into a product that has a greater added value. In manufacturing processes, there is operational waste that is popularized by Toyota Production System. Operational waste that will be used as the topic of researchers focuses on defect. Defect is a factor in the manufacturing process that can affect the outcome of the product. Defects can occur at every step of the manufacturing process, both from input to process to output. The concept of this research was chosen because during the manufacturing process are widely faced with the findings of defect that affect the outcome of products related to the "quality" where this factor is one of the

\footnotetext{
${ }^{1}$ Agyl Adriyadhi S and Moses Laksono Singgih are with Department of Management Technology, Institut Teknologi Sepuluh Nopember, Indonesia. Email: moseslsinggih@ie.its.ac.id.
}

benchmarks for customer satisfaction. For series products (products that are in production continuously and usually have a sequential number) consistent quality aspects become the main focus for the customer or the owner of the product. Therefore, the problem is necessary to do risk management to minimize defects in product outcomes and to increase awareness both at the management level as well as in executing production of products manufacturing activities.

\section{METHOD}

In 2007, analyzing the causes of electrical energy losses due to interference (electrical distribution network failure mode there are twelve electrical pole damage, power cord, lightning rod, connectors, jumpers, relays, insulators, Transformers, PMT and PMS switches, Buster, MCB, and limiter and gauges) with the FTA and FMEA methods and their mitigation recommendations. Priority improvement that must be done by the PLN based on the consideration of the effects of damage, frequency of damage, and the method of damage control as follows: Damage caused by the transformer[1]. In 2011 Ishikawa diagram or fishbone diagram is used to find the main cause of natural failure in the production of ceramic tiles. The calculation of RPN using FMEA is performed and found that the oven and Press machine have the highest RPN. Then again done analysis of Fishbone diagram for both machines to look for the root of the problem[2]. In 2017 analyzes the constraints that occur in toll road construction. The root cause of the problem is searched using Fishbone diagrams. Then FMEA is used to determine the critical risks that should be immediately solve[3]. In 2018 analyze the cause of the fishbone work accident to find the cause of failure. Then FMEA is used to mitigate errors and create risk maps to find out which failure mode is most urgent to complete[4].

\section{CONCEPT OF RISK, Risk MANAGEMENT FISHBONE \& FMEA}

\section{A. Risk}

Risks associated with uncertainty. This happens due to less or unavailability of information and insufficient data to predict what will happen. Something uncertain (uncertain) can have two possible consequences of being profitable or detrimental. Unfavorable uncertainty is referred to opportunity, while unfavourable uncertainty is referred to risk [5]. 
The $1^{\text {st }}$ International Conference on Business and Management of Technology (IConBMT)

August 3rd 2019, Institut Teknologi Sepuluh Nopember, Surabaya, Indonesia

\section{B. Risk Management}

Risk management is a method by which management is used to address issues caused by risk. Implementation of management functions in overcoming risk, especially the risks faced by organizations, institutions, companies, families, and the public. So the activities of planning, organizing, arranging, organizing, and supervising (including evaluating) which can be seen in Figure 1 are a risk mitigation program [6].

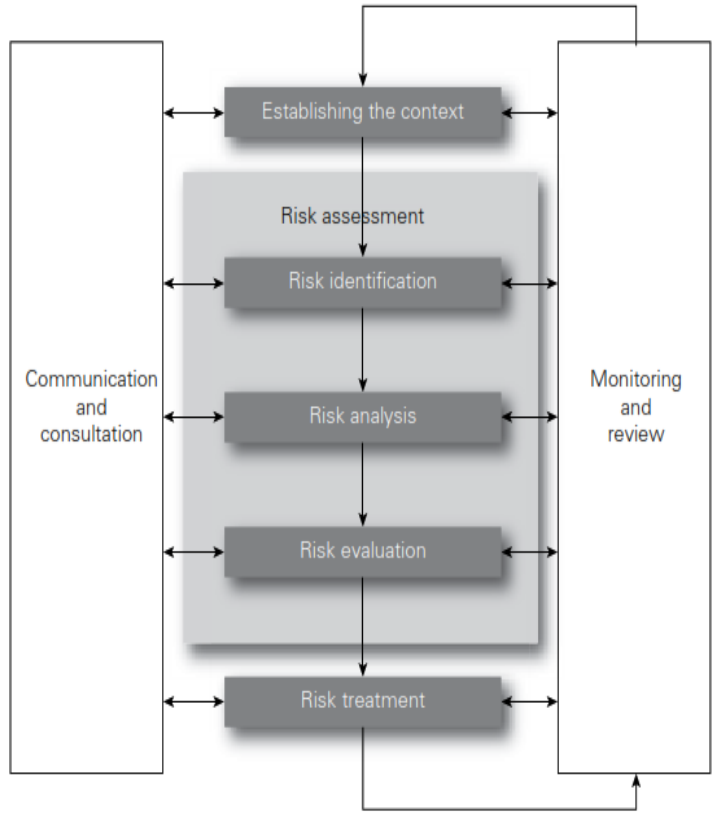

Figure 1. Activities of Risk Mitigation

\section{Cause effect diagram fishbone}

This diagram is also known as a fish bone diagram because it resembles a fish-like shape. It is also known as Ishikawa diagram because the first time was Prof. Ishikawa who originated from Japan. This Diagram is used to analyze and find the factors that are specifically affected in determining the quality characteristics of the results of the work, looking for the real causes of the problem. There are 4 specific main cause factors that should be observed: work method, machine/tool used, raw material, and work measurement. The example of fishbone diagram can be seen in Figure 2. The cause and effect Diagram have several advantages:

1. Analyze the field condition or actual for the purpose of improving product quality \& service, reduce costs \& efficient use of resources.

2. Reduce the situation or condition that causes the complain of the consumer and inconsistency in the product.

3. Standardizing operations on existing and future processes. To train and monitor personnel in conducting remediation activities in accordance with the results of decision resolution of the problem.

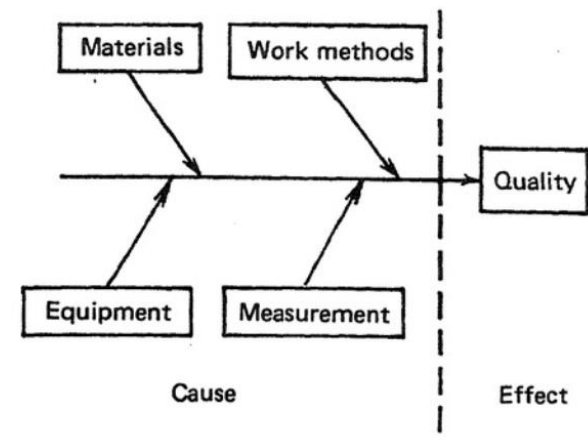

Figure 2. Fishbone Diagram

\section{FMEA}

Failure Mode and Effect Analysis (FMEA) is a method of non-conformance analysis and errors arising from the design process of a draft work. Failure mode and Effects Analysis form a stage that contains key points in the design process that could potentially be misappropriate and error. Both of these things can happen in the production process on the product to be made. FMEA is used to identify possible failure modes, causes of failure, and the consequences of such failures. Good and precise identification will improve overall product reliability and safety.

FMEA can be explained as a group of events projected to

- Recognize and evaluate the potential failure of a product or process and its effects.

- Identify actions that could eliminate or reduce the chance of potential failures.

- Document the process.

In the use of FMEA method, it is necessary to understand the constituent elements of FMEA, including Severity, Occurrence, Detection, and Risk Priority Number (RPN). Severity is an indicator that describes how significant the result is from a failure if it occurs. Severity is determined without considering other indicators such as occurrence and detection that only consider the description of failure and the description due to failure if occurred [7]. According to Stamatis there are 4 types of Failure and Mode Effect Analysis documentation [6]:

1) Methodologies of FMEA

Methodologies of FMEA is used to analyze systems and subsystems on initial concepts and designs. FMEA of is a type of FMEA focused on the potential failure modes between functions of systems that are system-deficient and aimed at maximizing the quality, reliability, cost and maintainability of a system. The Output generated from the FMEA of is as follows:

1. A list of potential failure modes compiled based on the RPN level.

2. The potential list of system functions that can detect potential failure modes.

3. List the potential of design actions to eliminate failure modes, safety issues, and reduce the occurrence level. 
The benefits of the FMEA of are as follows:

1. Help choose an optimal system design alternative.

2. Help determine the prediction (forecasting).

3. Assist in defining the basis for an existing system level diagnosis procedure.

4. Increase the likelihood that potential problems will be considered for actionable.

5. Identifying potential system failures and interactions with other systems and subsystems.

\section{2) Design FMEA}

FMEA Design is used to analyze products before they are released in manufacturing. FMEA design is a type of FMEA focused on Failure mode caused by design flaws and aims to maximize the quality, reliability, cost and maintainability of a design. Output generated from FMEA design is as follows:

1. A list of potential failure modes compiled based on the RPN level.

2. List of potential of critical and significant characteristics.

3. A list of potential of design actions that can be done to eliminate the mode of failure, security and reduce the level of occurrence.

4. List of potential of the parameters for the appropriate testing, inspection or detection methods.

5. The potential list of actions that should be done for critical and significant characteristics.

The benefits of FMEA design are as follows:

1. Create a priority for an existing design upgrade action.

2. Documenting the reasons used for changes made.

3. Provide information to help verify product design and testing.

4. Help identify critical or significant characteristics.

5. Assist in the evaluation of the needs and design alternatives to be made.

6. Help identify and eliminate potentially emerging security problems.

7. Identifying potential system failures and interactions with other systems and subsystems.

3) The FMEA process

The FMEA process is used to analyze manufacturing and assembly processes. The FMEA process is a type of FMEA focused on Failure mode due to the shortage of existing processes or assemblies. The Output generated from the FMEA process is as follows:

1. The potential list of failure modes based on RPN ratings.

2. A list of potential of critical and/or significant characteristics.

3. The potential list of action recommendations to refer to critical and significant characteristics.

The benefits of the FMEA process are as follows:

1. Identify the process differences and offer corrective action recommendations.
2. Identifying critical and/or significant characteristics and assisting in developing control planning.

3. Make priority of the corrective action.

4. Assist in manufacturing analysis or assembly process.

4) FMEA Service

FMEA service is used to analyze services before reaching consumers. The FMEA Service focuses on the failure modes caused by the system or process. Output generated from the FMEA service is as follows:

1. List of potential errors based on RPN ratings.

2. A list of potential of critical or significant task characteristics or processes.

3. List the potential of a bottleneck process or task.

4. List of potential to eliminate errors.

5. List of potential of system surveillance/process functions.

The benefits of FMEA service are as follows:

1. Assists in analyzing the flow of work.

2. Assist in analyzing the system or process.

3. Identify task differences.

4. Compile priorities for corrective actions

\section{E. Severity}

Severity is the assessment of the seriousness of the effect of the potential failure mode of the impact/intensity of the event affects the outcome of the process. In this we have to determine all failure modes based on the functional requirements and their effects. An example table of severity is given below.

TABLE 1.

SEVERITY CLASSIFICATION

\begin{tabular}{lcl}
\hline \multicolumn{1}{|c}{ Classification } & Score & \multicolumn{1}{c}{ Severity } \\
\hline None & 1 & No Effect \\
Very Minor & 2 & $\begin{array}{l}\text { Buyers will not be disturbed by failures that occur } \\
\text { and will not feel a change in product performance. } \\
\text { Sometimes there are warnings for nonvital errors }\end{array}$ \\
Minor & 3 & $\begin{array}{l}\text { Buyers are slightly distracted and slight failure } \\
\text { affects product performance. Most have warnings } \\
\text { for nonvital errors }\end{array}$ \\
Very Low & 4 & $\begin{array}{l}\text { Buyers are slightly distracted and slight failure } \\
\text { affects product performance. Failures that occur } \\
\text { do not require rework and there is always a } \\
\text { warning for nonvital errors } \\
\text { Luyers will feel dissatisfied and slight failure } \\
\text { affects the product's performance. Failure on } \\
\text { nonvital parts of the product will experience } \\
\text { rework } \\
\text { Buyers feel uncomfortable and failures that occur } \\
\text { can decrease product performance, but can still be } \\
\text { operated and secured. Nonvital parts of the } \\
\text { product cannot be worn. }\end{array}$
\end{tabular}

High

7 Buyer dissatisfied and failure affects the process. Rework is done on a defective part. The product performance deteriorates but is still functioning and safe.

Very High $\quad 8$ Buyers are very dissatisfied and failures that occur greatly affect the process. Faulty equipment and 
The $1^{\text {st }}$ International Conference on Business and Management of Technology (IConBMT)

August 3rd 2019, Institut Teknologi Sepuluh Nopember, Surabaya, Indonesia

products may not operate.

Hazardous with 9 Most likely dangerous. Product can be Warning

Hazardous without

Warning

\section{F. Occurrence}

Occurrence is the possibility of how often one causes the failure mode to occur. In this step, it is necessary to see the cause of the failure and how many times it occurs.

TABLE 2.

OCCURRENCE CLASSIFICATION

\begin{tabular}{cl}
\hline \hline & \multicolumn{1}{c}{ Occurrence } \\
\hline Score & \multicolumn{1}{c}{ Description } \\
\hline 1 & Failure highly unlikely \\
2 & Rare number of failure likely \\
3 & Very few failures likely \\
4 & Few failures likely \\
5 & Occasional failures likely \\
6 & Medium number of failures likely \\
7 & Moderately high number of failures likely \\
8 & High number of failures likely \\
9 & Very high number of failures likely \\
10 & Failure almost certain \\
\hline \hline
\end{tabular}

\section{G. Detection}

In detection dimension, risk can be detected when checked by personnel involved in product production process, the detection category is displayed on Table 3.

TABLE 3 .

DETECTION CLASSIFICATION

\begin{tabular}{cl}
\hline \hline \multicolumn{1}{c}{ Detection } \\
\hline Score & \multicolumn{1}{c}{ Description } \\
\hline 1 & Very high probability of detection \\
2 & High probability of detection \\
3 & Controls will almost certainly detect \\
4 & Manufacture controls are moderately effective \\
5 & Manufacture controls have an even chance of working \\
6 & Manufacture controls may miss the problem \\
7 & Manufacture controls are likely to miss the problem \\
8 & Manufacture control have a poor chance of detection \\
9 & Unproven, unreliable Manufacture /poor chance for detection \\
10 & No design technique available / controls will not detect \\
\hline \hline
\end{tabular}

\section{H. Risk Priority Number (RPN)}

After deciding the severity, occurrence and detection numbers, the RPN can be easily calculated by multiplying these 3 numbers: RPN $=$ Severity $\times$ Occurrence $\times$ Detection. The small RPN is always better than the high RPN. The assessment results are grouped by category below.

TABLE 4.

RISK PRIORITY NUMBER CLASSIFICATION

\begin{tabular}{|c|c|c|}
\hline Score & Rating & Detection \\
\hline$X>500$ & $\begin{array}{l}\text { Critical } \\
\text { Risk }\end{array}$ & $\begin{array}{l}\text { Critical Level } \sim \text { Do not permit activity to } \\
\text { commence. }\end{array}$ \\
\hline $201 \leq X<500$ & High Risk & $\begin{array}{l}\text { Risk Must be mitigated and risk level need } \\
\text { to reduce to moderate or minor risk. }\end{array}$ \\
\hline $101 \leq X<200$ & $\begin{array}{l}\text { Moderate } \\
\text { Risk }\end{array}$ & $\begin{array}{l}\text { Investigate and monitoring controls to } \\
\text { minimize risk. }\end{array}$ \\
\hline$X<100$ & $\begin{array}{l}\text { Minor } \\
\text { Risk }\end{array}$ & $\begin{array}{l}\text { Acceptable risk. Review when process } \\
\text { changes, or when circumstances change. }\end{array}$ \\
\hline
\end{tabular}

\section{RESULTS AND DISCUSSION}

At the risk mitigation phase of this research results from the method FMEA (Failure Mode \& Effect analysis), with this mitigation is expected to reduce, minimizing even eliminating the impact of risk and causes of risk result in defect. The risk mitigation process uses criteria to rank the occurrence of severity and detection is selected according to analyzing the records of past failures of any production process. First, the basic requirements of the manufacturing process are studied and then the potential failure mode of the specified process is found. After that defect mode failure is recorded with their severity value. The occurrence rate for potential causes and their prevention is also calculated. The detection value is set to Failure mode and eventually the RPN value is calculated. Result FMEA Chart of DU Base Frame product shown in Table 5.

After obtaining the ranking of the RPN in the FMEA process further provides a proposed improvement to the failure modes that are in the high-risk category show on Table 6. The proposed detail improvement in this case study is only given at risk that includes the high-risk category where defects arising from three risks with high risk have an effect that affects the function and age of the product. For moderate risk \& minor risk proposals improvements in general in the form of warnings on each personnel involved to understand the working procedure before starting a production activity.

TABLE 5.

RESULT FMEA CHART OF DU BASE FRAME

\begin{tabular}{cccc}
\hline \hline Ranking & Failure Mode & RPN & Risk Classification \\
\hline 1 & Corrosion on the machined surface & 288 & High Risk \\
2 & Lack of roughness (Too smooth - Blasting process to long) & 288 & High Risk \\
\hline \hline
\end{tabular}


The $1^{\text {st }}$ International Conference on Business and Management of Technology (IConBMT) August 3rd 2019, Institut Teknologi Sepuluh Nopember, Surabaya, Indonesia

\begin{tabular}{|c|c|c|c|}
\hline 3 & Sagging (Paint running or hanging like curtains on vertical surfaces) & 256 & High Risk \\
\hline 4 & Lack of roughness (Too smooth - incorrect blasting material size) & 224 & High Risk \\
\hline 5 & Inclusion in the paint & 200 & Moderate Risk \\
\hline 6 & Surface material salt & 140 & Moderate Risk \\
\hline 7 & Too much dust attached & 140 & Moderate Risk \\
\hline 8 & Coating thickness (not as specified) & 140 & Moderate Risk \\
\hline 9 & Coating color (not as specified) & 140 & Moderate Risk \\
\hline 10 & Thin coating thickness in the edges area & 140 & Moderate Risk \\
\hline 11 & Incorrect diameter & 112 & Moderate Risk \\
\hline 12 & Hole drilled on the wrong place & 112 & Moderate Risk \\
\hline 13 & Obliqueness on hole position & 112 & Moderate Risk \\
\hline 14 & Rusty Material, Mill scale material & 112 & Moderate Risk \\
\hline 15 & Paint surfaces appeared like orange peel & 112 & Moderate Risk \\
\hline 16 & Pin Holing & 112 & Moderate Risk \\
\hline 17 & Distortion & 96 & Moderate Risk \\
\hline 18 & Holey object & 96 & Moderate Risk \\
\hline 19 & Machining surface are painted & 96 & Moderate Risk \\
\hline 20 & Temperature \& humidity more or less than the number & 84 & Moderate Risk \\
\hline 21 & Rusty Material, Mill scale material (Machine failure) & 84 & Moderate Risk \\
\hline 22 & Dry Spray (porous, sandpaper like surface of the paint) & 84 & Moderate Risk \\
\hline 23 & Wrinkling (Small wrinkles through or partly through the paint) & 84 & Moderate Risk \\
\hline 24 & Not cutting to the line (Lack of concentration Operator) & 80 & Moderate Risk \\
\hline 25 & Assy not match with drawing (Incorrect jig is used) & 80 & Moderate Risk \\
\hline 26 & Assy not match with drawing (Jig is set up incorrectly) & 80 & Moderate Risk \\
\hline 27 & Assy not match with drawing (Unknown movement during Fit up before tack weld) & 80 & Moderate Risk \\
\hline 28 & Spatter & 80 & Moderate Risk \\
\hline 29 & Rough surface (Machining rework) & 72 & Minor Risk \\
\hline 30 & Untidy Weld & 64 & Minor Risk \\
\hline 31 & Over penetration & 64 & Minor Risk \\
\hline 32 & Dimension doesn't meet the specification (Flatness) & 64 & Minor Risk \\
\hline 33 & Not cutting to the line (Machine is not set up properly before use) & 60 & Minor Risk \\
\hline 34 & Incorrect shape produced (Incorrect program loaded) & 60 & Minor Risk \\
\hline 35 & Incorrect shape produced (Incorrect sheet loaded) & 60 & Minor Risk \\
\hline 36 & Incorrect shape produced (Incorrect set up) & 60 & Minor Risk \\
\hline 37 & Assy not match with drawing (Jig is not used) & 60 & Minor Risk \\
\hline 38 & Fish Eyes (Painting) & 56 & Minor Risk \\
\hline 39 & Porosity (Welding speed are too fast) & 50 & Minor Risk \\
\hline 40 & Porosity (Poor weld preparation / cleaning) & 50 & Minor Risk \\
\hline 41 & Crack & 50 & Minor Risk \\
\hline 42 & Lack of Penetration & 50 & Minor Risk \\
\hline 43 & Rough surfaces (Spindle work too fast) & 48 & Minor Risk \\
\hline 44 & Dimension doesn't meet the specification (Incorrect set up) & 48 & Minor Risk \\
\hline 45 & Dimension doesn't meet the specification (Height) & 42 & Minor Risk \\
\hline 46 & Mark in incorrect position & 40 & Minor Risk \\
\hline 47 & Lack of Fusion (Object covered by dirt) & 40 & Minor Risk \\
\hline 48 & Lack of Fusion (Incorrect Welding technique) & 40 & Minor Risk \\
\hline 49 & Slag Inclusion & 40 & Minor Risk \\
\hline 50 & Porosity (Over Arc Length) & 40 & Minor Risk \\
\hline
\end{tabular}


The $1^{\text {st }}$ International Conference on Business and Management of Technology (IConBMT)

August 3rd 2019, Institut Teknologi Sepuluh Nopember, Surabaya, Indonesia

\begin{tabular}{lccc}
\hline \hline 51 & Crack (Welding doesn't follow the WPS) & 30 & Minor Risk \\
52 & Crack (Electrode doesn't match with given specification) & 30 & Minor Risk \\
53 & Lack of Penetration (Incorrect groove dimension) & 30 & Minor Risk \\
54 & Lack of Fusion (Lack of heat input) & 30 & Minor Risk \\
55 & Porosity (Wet Electrode) & 30 & Minor Risk \\
56 & Porosity (Welding doesn't follow the WPS) & 30 & Minor Risk \\
\hline \hline
\end{tabular}

TABLE 5.

PROPOSED FIXES FOR RISKS INCLUDED IN THE HIGH-RISK CATEGORY

\begin{tabular}{|c|c|c|c|}
\hline \multicolumn{4}{|r|}{ HIGH RISK } \\
\hline No. & Process & RPN & Proposed Fixes \\
\hline 1 & Milling & 288 & $\begin{array}{l}\text { 1. Milling process is done under the condition of MQL (Minimum Quantity Lubrication) with speed } 1500 \mathrm{Rpm} \text {, Feed Rate } \\
1000 \mathrm{~mm} / \mathrm{min} \text { with depth of cut } 1 \mathrm{~mm} \text {. } \\
\text { 2. Clean the grinding material using the same MQL fluid. } \\
\text { 3. Dry the surface that has been in machining then spray liquid tactyl } 506 \text { Aerosol Spray }\end{array}$ \\
\hline 2 & Blasting & 288 & $\begin{array}{l}\text { 1. Use steel type Grit \& Steel Shoot. } \\
\text { 2. Air pressure } 80 \mathrm{psi} \text {, with blast area } 21.5 \mathrm{Cm} / \mathrm{min} \text {. } \\
\text { 3. Do an anchor test at least } 3 \text { times with a varied spot area }\end{array}$ \\
\hline 3 & Painting & 256 & $\begin{array}{l}\text { 1. Mixing paint with thinner should match TDS (Technical Data Sheet) type of paint. } \\
\text { 2. Distance spray and application time } \min 20 \mathrm{~cm} / \mathrm{s} \text {. } \\
\text { 3. Painting Operator must follow training and field test }\end{array}$ \\
\hline 4 & Blasting & 224 & $\begin{array}{l}\text { 1. Check the sandblasting material before starting the process. } \\
\text { 2. Use steel type grit \& Steel Shoot corresponding to the procedure. }\end{array}$ \\
\hline
\end{tabular}

\section{CONCLUSION}

From the results of the research and calculation of data obtained, it can be concluded:

1. It is identified as much as 56 defect risk in the entire production process starting from the marking process, manual \& Auto Cutting, fit-up, welding, drilling \& milling machining process, blasting and painting and has done the process of risk mitigation plan that Focus on the Traveler sheet \& fabrication procedure documents on each process.

2. From the calculation result there are 4 high risk with RPN between 201 - 500 namely: milling process (RPN $=288)$, blasting process $(\mathrm{RPN}=288 \& 224)$ and painting process $(\mathrm{RPN}=256)$.

3. For preventive action need a detailed explanation on the procedure document and the traveler's sheet. Establishing good communication between the fields and carrying out tasks according to the SOP with full awareness and responsibility can be a long-term evaluation.

As for some advice that can be done for research and the company is:

1. The need for good preparation and intensive discussion of all fields before starting a product production so that the process can run more efficiently and effectively.

2. Know and understand the condition of man power, tools and machines used for the procedures made in accordance with the actual conditions.

3. Conducting periodic maintenance on the appliance, machinery and maintaining the working environment always condition can help increase the consecration of each personnel in the workshop.

4. Conduct training awareness internally and periodically can foster a sense of care for the SOP of each section.

\section{REFERENCES}

[1] H. A. Surasa, "Analisis Penyebab Losses Energi Listrik Akibat Gangguan Jaringan Distribusi Menggunakan Metode Fault Tree Analysis Dan Failure Mode and Effect Analysis Di PT . PLN ( Persero ) Unit Pelayanan Jaringan Sumberlawang," Universitas Sebelas Maret, 2007.

[2] P. H. Tsarouhas and D. Arampatzaki, "Application of Failure Modes and Effects Analysis (FMEA) of a ceramic tiles manufacturing plant," in 1st Olympus International Conference on Supply Chains, 2010, pp. 1-17.

[3] B. Purwanggono and A. Margarette, "Risk assessment of underpass infrastructure project based on ISO 31000 and ISO 21500 using fishbone diagram and RFMEA (Project Risk Failure Mode and Effects Analysis) method," in IOP Conference Series: Materials Science and Engineering, 2017, vol. 277 , no. 1.

[4] F. Suryani, "Penerapan metode diagram sebab akibat (fish bone diagram) dan FMEA (Failure Mode and Effect) dalam menganalisa resiko kecelakan kerja di PT. Pertamina," J. Ind. Serv., vol. 3, no. 2, pp. 63-69, 2018.

[5] P. Hopkin, Fundamentals of Risk Management : Understanding, Evaluating and Implementing Effective Risk Management, 5th Ed. London: Kogan Page, 2018.

[6] D. H. Stamatis, Introduction to Risk and Failures: Tools and Methodologies. London: CRC Press, 2014.

[7] C. Carlson, Understanding and Applying the Fundamentals of FMEAs. Arizona: ReliaSoft Corporation, 2014. 